\title{
Attenuation of Ischaimia Reperfusion Induced Myocardial Cell Injury in Rat Heart by Calpastatin
}

\author{
Rashmi Arora \\ Sri Aurobindo Institute of Pharmacy, Indore, Madhya Pradesh-453555, India
}

\begin{abstract}
Myocardial ischaemia reperfusion is associated with activation of intracellular death proteases known as calpains. Isolated rat heart was subjected to 30 min ischaemia followed by reperfusion for 120min. The effect of calpain inhibitor calpastatin in induced myocardial injury assessed in terms of infract size measured macroscopically, release of LDH and CK have been investigated. Agarose gel electrophoresis was used to assess the DNA fragmentation. TUNEL staining was done to investigate the apoptotic index. Calpastatin has attenuated ischaemia reperfusion induced increase in LDH,CK, myocardial infarct size ,DNA smearing and apoptotic index. It may be concluded that inhibition of intracellular death proteases prevented ischaemia reperfusion induced myocardial cell injury in terms of apoptosis and necrosis.
\end{abstract}

Keywords: Calpain, Calpastatin , Myocardial injury, Mitochondrial damage, Rat heart

\section{Introduction}

Apoptosis may lead to necrotic cell death [1]-[4]. The transition from reversible to irreversible injury is characterized by the development of a severe membrane permeability defects that allows the unregulated influx of divalent and trivalent cations including calcium[5]. Reperfusion is associated with rise in calcium [6] which leads to activation of calpain-a calcium dependent membrane protease implicated in necrotic cell death [6] and is involved in signal transduction of apoptosis [7].

Tissue damage in ischaemic areas involves both apoptosis and necrosis and calpain participate in both the processes [8]. Reperfusion leads to rise in calcium level which causes calpain -a calcium dependent protease activation, implicated in damage of myocardial structural proteins leading to membrane break down and eventually cell death [9]. Reperfusion results in sodium ion influx followed by $\mathrm{Ca}^{2+}$ accumulation which may activate calpain and consequently produce cleavage of associated proteins. The cleaved activated fragments acts on mitochondria causing its dysfunction and release of pro-apoptotic factors resulting in DNA fragmentation and cell death. On the other hand release of cytochrome $-\mathrm{c}$ produces depletion of ATP stores [6] and lead to necrotic cell death [10]. The transition from reversible to irreversible injury is characterized by the development of severe membrane permeability defects [5],[11] and degradation of membranous proteins [12]. The mode of cell death shifts from apoptotic to necrotic due to use of ATP stores by apoptosis[2]. Therefore, apoptosis may lead to necrotic cell death [1]-[4].

During ischaemia and reperfusion, calpain activity is increased through both an increase in the expression of calpains and a decrease in the expression of its endogenous inhibitor- Calpastatin [13]. Calpastatin suppresses conformational changes in calpain molecule during the initial stages of its activation and inhibits binding to its cell membrane and degradation of membrane proteins [12],[14]. The selective inhibition of calpain activity by calpastatin [15] has improved function of heart which were declined as a result of ishaemia and reperfusion.
The study describes that the inhibition of calpain structural modification by calpastatin showed marked improvement in biochemical index, apopotic and necrotic indices in ishaemia reperfusion induced myocardial injury in rat heart.

\section{Materials and Methods}

\subsection{Drugs}

Calpastatin (Calbiochem, CA, USA), Proteinase K(SigmaAldrich, St. Louis, USA) and RNAse(Hi Media, Mumbai, India) were used to carry out the study.

\subsection{Animals}

Wistar albino rats of either sex were used to carry out studies. Rats were heparinised and sacrificed by stunning; heart rapidly excised and immediately mounted on Langendroff's apparatus [16].The preparation was perfused with Krebs-Heinslet (K-H) solution $\mathrm{pH} 7.4$, maintained at $37^{\circ} \mathrm{C}$ and bubled with $95 \% \mathrm{O}_{2}$ and $5 \% \mathrm{CO}_{2}$. Coronary flow rate was maintained $6-9 \mathrm{ml} / \mathrm{min}$ and perfusion pressure was kept constant at $70 \mathrm{~mm} \mathrm{Hg}$. Global ischaemia was produced for $30 \mathrm{~min}$ by closing the inflow of physiological solution and it was followed by reperfusion for $120 \mathrm{~min}$. Two thin electrodes fixed at ventricular apex and origin of aorta were employed to record ECG(BPL, MK 801, Banglore, India) for monitoring heart rate.

\subsection{Infarct size Measurement}

Infarct size was measured and expressed as percentage of total left ventricular volume (\%LVV) and left ventricular weight $(\% \mathrm{LVW})$ respectively by Volume and Weight method. [17],[18].

\subsection{DNA extraction and Gel electrophoresis}

It was carried out for measuring the extent of necrosis of myocardium [19]. The concentration of DNA was determined spectrophotometrically at $260 \mathrm{~nm}$. Protein contamination of DNA was accessed by determining the 


\section{International Journal of Science and Research (IJSR) \\ ISSN (Online): 2319-7064 \\ Index Copernicus Value (2013): 6.14 | Impact Factor (2014): 5.611}

ratio of absorbance at $260 \mathrm{~nm}$ and $280 \mathrm{~nm}$ which should not be more than 1.75. To detect the internucleosomal cleavage, 10-12 $\mu \mathrm{g}$ of extracted DNA was added to equal volume of loading dye and it was loaded in the well. Electrophoresis was carried out using $1.8 \%$ agrose gel in $1 \mathrm{X}$ TBE buffer for $1.5 \mathrm{hrs}$ at $400 \mathrm{~mA}$ and $3 \mathrm{~W}$ in submarine electrophoresis unit(Pharmacia Biotech, Freibury, Germany). Ethidium bromide was added to gel for DNA detection.

\section{TUNEL Staining}

TUNEL positive cardiomyocytes were counted and apoptotic index was calculated using(1) the formula [20].

Number of TUNEL positive

cell nuclei

Apoptotic Index = $\mathrm{x} 100$

\section{Estimation of LDH}

LDH was estimated in coronary effluent by 2,4-DNPH method [21] spectrophotometrically at $440 \mathrm{~nm}$.

Optical density of Test (O.D. ${ }_{\mathrm{T}}$ ) and control (O.D.C) was measured (2) against distilled water.

$$
\text { Net optical density of test }\left(O \cdot D_{T_{a}}\right)=O . D_{\cdot T}-O . D \cdot C
$$

Enzyme activity was calculated from standard plot by making O.D.Tnon $\mathrm{Y}$-axis and extrapolating it to corresponding enzyme activity on $\mathrm{X}$-axis.

\section{Estimation of CK}

CK was estimated in coronary effluent and Optical density of test (O.D.T), standard(O.D.S) and blank(O.D.B) was measured spectrophotometrically(3) against distilled water at $520 \mathrm{~nm}[22]$.

$$
\mathrm{CK}(\mathrm{IU})=\frac{\text { O.D. }- \text { - O.D.B } 10^{3} \times \text { Creatinine taken }(\mu \mathrm{M})}{\text { O.D.s-O.D.B }} \times \frac{\mathrm{X}}{\text { Incubation time } \mathrm{x} \text { coronary effluent }}
$$

The protocol has been designed to evaluate the effects of peptide calpain inhibitor Calpastatin on ischaemiareperfusion induced myocardial injury (Fig. 1).

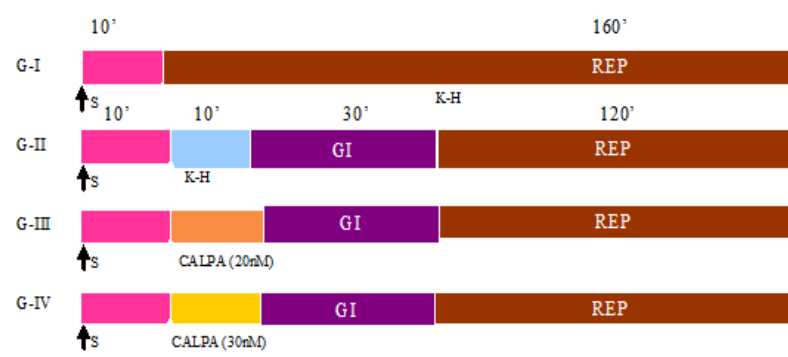

Figure 1: Diagrammatic representation of experimental protocol S-stabilization; K-H perfusion with K-H solution; GI- global ischaemia; REP- reperfusion with K-H solution.

\section{Results and Discussion}

The present study describes the changes in terms of lactate dehydrogenase $(\mathrm{LDH})$ and creatine kinase $(\mathrm{CK})$. Maximum increase in the release of LDH is noted either immediately or $30 \mathrm{~min}$ after reperfusion. The noted release of $\mathrm{LDH}$ immediately after reperfusion may be due to sustained ischaemia and late spurt in the release of LDH noted after 30 min of reperfusion may be as a result of reperfusion. Peak increase in the release of creatine kinase (CK) after 5 minutes of reperfusion is used as a measure of lethal cardiomyocyte injury. Apoptosis generate high molecular weight fragments which cannot be detected by agarose gel electrophoresis. TUNEL (terminal deoxynucleotidyltransferase mediated UTP nick end labeling) technique has been employed to determine the apoptotic cell death (Fig.1 sham control). Myocardial ischaemia and reperfusion is associated with the activation of calpains which consequently produce apoptotic cell death through release of proapoptotic factors. That's why perhaps global ischaemia for $30 \mathrm{~min}$ followed by reperfusion for 120 min has significantly increased apoptotic index estimated by TUNEL staining (Fig.2-Fig.5).

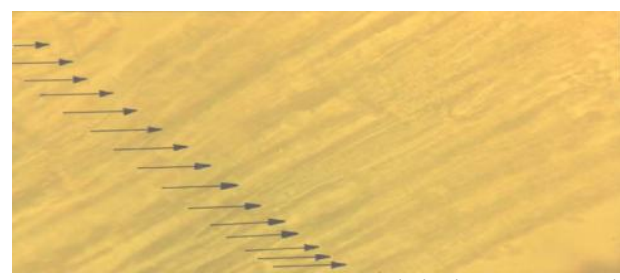

Figure 2: TUNEL +ve nuclei sham control

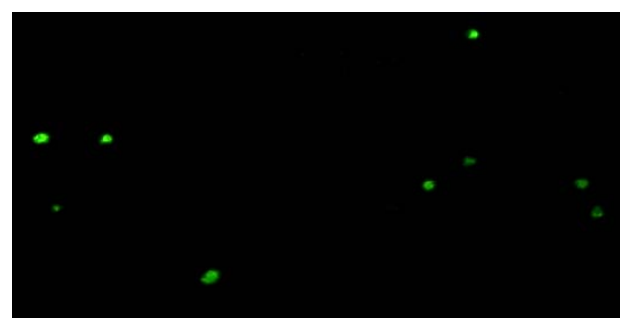

Figure 3: TUNEL +ve nuclei control

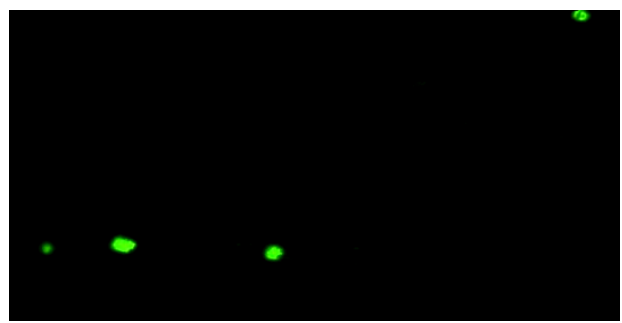

Figure 4: TUNEL +venuclei(Calpastatin 20nM)

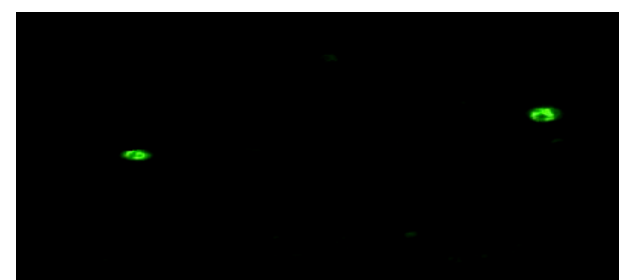

Figure 5: TUNEL + venuclei(Calpastatin 30nM)

Calpain is specifically inhibited by calpastatin which is a peptide inhibitor .It suppresses the conformational changes in the calpain structure necessary during the initial stages of its activation and binding to the cellular membranes and consequent degradation of membrane proteins. The mechanism underlying the reperfusion induced necrotic cell death involves onset of mitochondrial permeability transition (MPT). Opening of permeability transition pores in mitochondria causes release of cytochrome $\mathrm{c}$ along with depletion of ATP and ultimately leads to necrotic (energetic) 


\section{International Journal of Science and Research (IJSR) \\ ISSN (Online): 2319-7064}

Index Copernicus Value (2013): 6.14 | Impact Factor (2014): 5.611

cell death. Hence global ischaemia for $30 \mathrm{~min}$ followed by reperfusion for $120 \mathrm{~min}$ has significantly increased necrotic cell death measured in terms of infarct size and release of $\mathrm{LDH}$ and $\mathrm{CK}$. The specific inhibition of calpain activity by calpastain may be responsible for the noted decrease in apoptotic index (Fig.6), infarct size (Fig.7) and release of CK(Fig.8) and LDH(Fig.9).

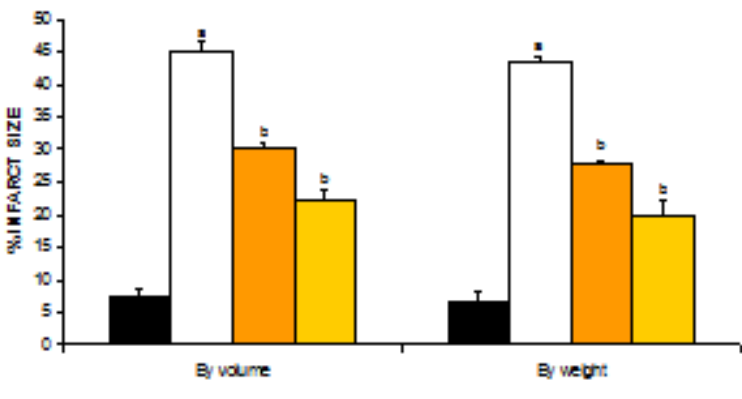

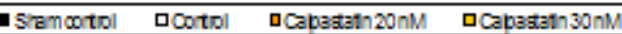

Figure 6: Effect of Calpastatin on Apoptotic Index

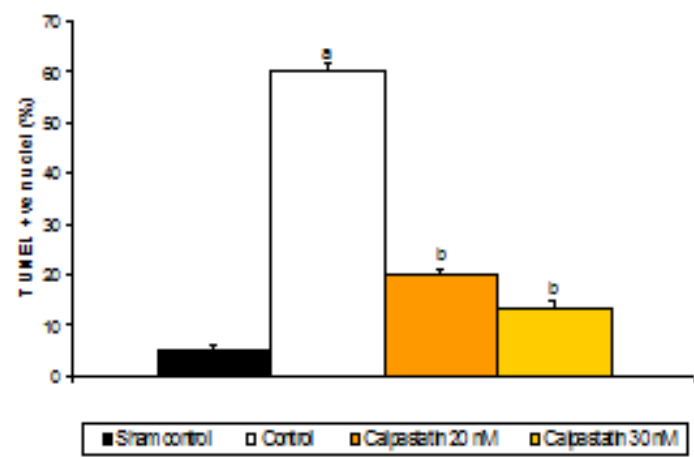

Figure 7: Effect of Calpastatin on infarct size

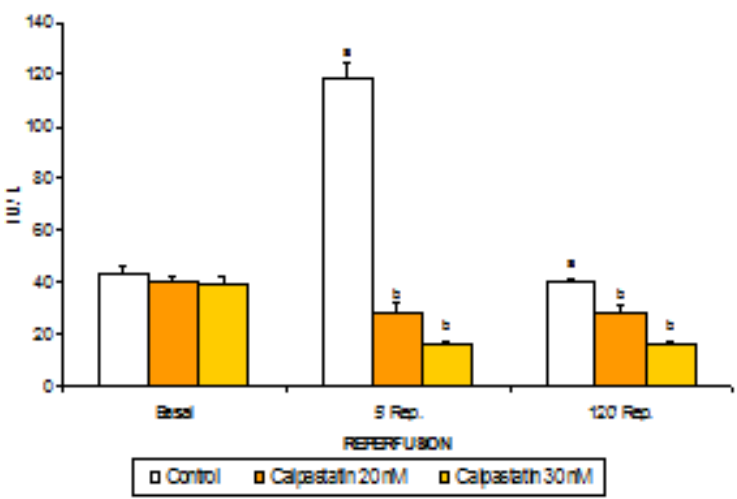

Figure 8: Effect of Calpastatin on CK release

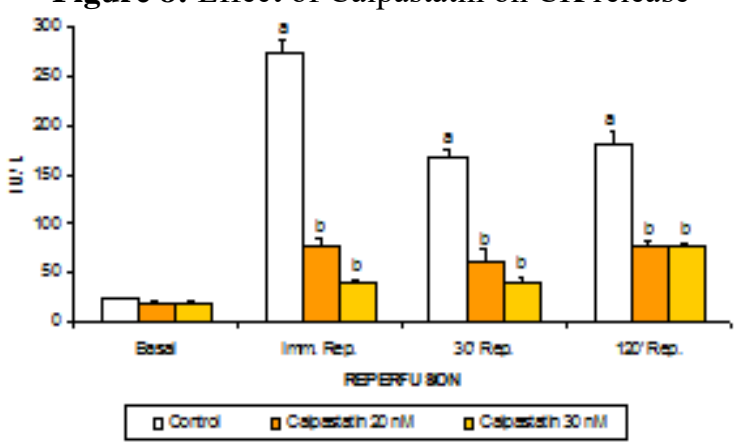

Figure 9: Effect of Calpastatin on LDH release
The mode of cell death shifts from apoptotic to necrotic because of use of ATP during apoptosis and consequent depletion of ATP store. Therefore atypical pattern of DNA fragmentation occured which likely represent a smear formation. Apoptosis and necrosis are reported to coexist in acute is chaemia and reperfusion. Thus it is possible to suggest that DNA smearing noted in present study may reflect apoptosis induced necrotic cell death. The specific inhibition of calpain activity by calpastain(20nM and 30nM) ultimately block apoptosis induced necrotic cell death may be responsible for the noted decrease in DNA smear formation. The noted inhibition of calpain activity by Calpastatin may be because of its peptide nature ) and consequent better membrane permeability and availability in the cytoplasm.

\section{Conclusion}

On the basis of results obtained in the present study, it may be concluded that

1) Isolated rat heart subjected to ischaemia of $30 \mathrm{~min}$ followed by reperfusion for 120 min produced significant increase in myocardial injury measured in terms of infarct size and release of LDH and CK. It produced marked increase in apoptotic index and DNA smearing. It suggests that ischaemia and reperfusion has produced apoptotic and apoptosis induced necrotic cell death in isolated rat heart.

2) The peptide inhibitor of calpain - calpastatin significantly decreased ischaemia-reperfusion-induced apoptotic index and attenuated ischaemia and reperfusion induced apoptotic cell death.

3) The peptide inhibitor calpastatin(20nM and $30 \mathrm{nM})$ have prevented ischaemia-reperfusion-induced increase in ventricular DNA smearing, which has occurred as a result of apoptotic-induced-necrotic cell death.

4) The peptide inhibitor calpastatin(20nM and $30 \mathrm{nM})$ significantly attenuated ischaemia-reperfusion-induced increase in myocardial infarct size and release of $\mathrm{LDH}$ and $\mathrm{CK}$. These results suggests that ischaemia and reperfusion induced necrotic injury has been prevented by calpastatin.

5) The compound calpastatin is effective to attenuate ischaemia-reperfusion-induced increase in apoptotic index, DNA smearing and myocardial injury. It may be due to the peptide nature of calpastatin and its better membrane permeability.

6) The proposed hypothesis (Fig.10)supports the above salient findings and shows the site of action of calpastatin to attenuate ischaemia -reperfusion induced myocardial cell death. 


\section{International Journal of Science and Research (IJSR) \\ ISSN (Online): 2319-7064}

Index Copernicus Value (2013): 6.14 | Impact Factor (2014): 5.611

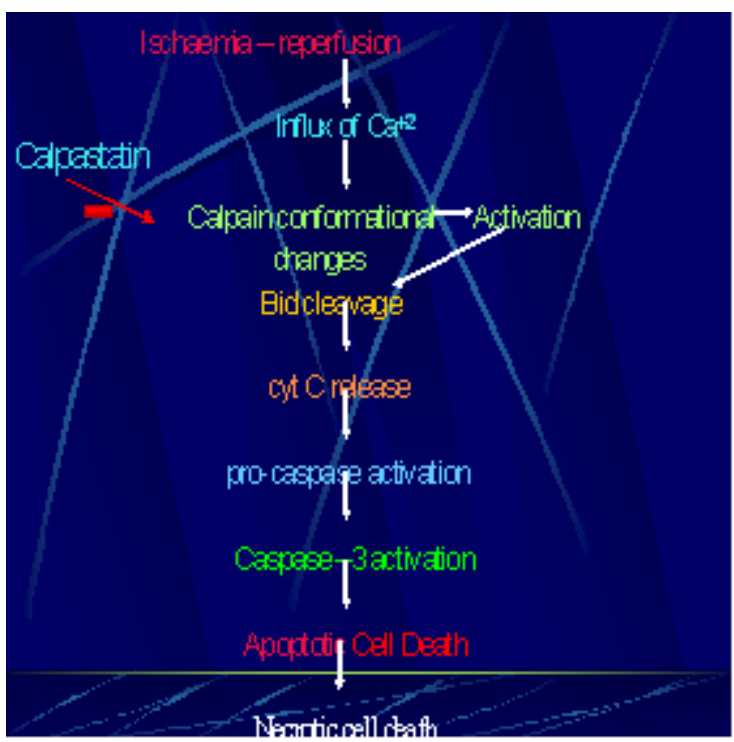

Figure 10: Proposed hypothesis for calpain activation and site of action of Calpastatin

\section{Acknowledgment}

Author extends her sincere thanks to Late Dr. Manjeet Singh (Department of Pharmaceutical sciences and Drug Research, Punjabi University Patiala,Punjab, India) for guidance in carrying out the study.

\section{References}

[1] Daemen, M.A., Van't Veer, C., Denecker, G. Heemskerk, V.H., Wolfs, T.G., Clauss, M., Vandenabeele, P. and Buurman, W.A. (1999). Inhibition of apoptosis induced by ischaemicreperfusion prevents inflammation, J. Clin. Invest.,104: 541-549.

[2] Nicotera, P. and Leist, M. (1997). Energy supply and the shape of death in neurons and lymphoid cells. Cell Death Differ.,4: 435-442.

[3] McCarthy, N.J., Whyte, M.K.B., Gilbert, C.S. and Evan, G.I. (1997). Inhibition of Ced3/ICE related proteases does not prevent cell death induced by oncogenes, DNA damage or the Bcl-2 homologue Bak. J. Cell. Bio.l, 136: 215-227.

[4] Ferrer, I., Martin, F., Serrano, T., Reirig, J., PerezNavarro, E., Alberch, J., Macaya, A. and Planas, A.M. (1995). Both apoptosis and necrosis occur following intrastrail and administration of excitotoxins. Acta. Neuropathol. (Berl).,90(5): 504-510.

[5] Buja, M.L. and Entmon, M.L. (1998). Modes of myocardial cell injury and cell death in ischaemic heart disease. Circulation. 14: 1355-1361.

[6] Chen, M., He, H., Zhan, S., Krajewaki, S., Reed, J.C. and Gottlieb, R.A. (2001). Bid is cleaned by calpain to an active fragment in vitro and during myocardial $\mathrm{I} / \mathrm{K} . J$ BiolChem, 276(33): 30724-30728.

[7] Goll, D.E., Thompson, V.F., Li, H., Wei, W. and Cong, J. (2003). The calpain system. Physiol Rev, 83: 731-801.

[8] Blomgren, K., Zhu, C., Wang, X., Karlsson, J-O, Leverin, A-L, Bahr, B.A., Mallard, C. and Hagberg, H. (2001). Synergistic activation of caspase-3 by m-calpain after neonatal hypoxia-ischemia. A. mechanism of "pathological apoptosis"? J BiolChem, 276: 1019110198.

[9] Yoshida,K.,Sorimachi,Y.,Fujiwara,M and Hironaka,K(1995). Calpain is implicated in rat myocardial injury after ischaemia or reperfusion.Jpn.Circ, 59:40-48.

[10] Kim, J.S., He, L., Qian T and Lemasters, J.J. (2003). Role of the mitochondrial permeability transition in apoptotic and necrotic death after ischaemia/reperfusion injury to hepatocytes. Curr. Mol. Med., 3(6): 527-535.

[11]Buja, M.L., Eigenbrodt, M.L. and Eigenbrodt, E.H. (1993). Apoptosis and necrosis: basic types and mechanism of cell death. Arch. Pathol. Lab. Med., 117: 1208-1214.

[12] Tatiana G. Sanzontova, Alexey A. Matskevich and Yuriy V. Arkhipenko (1999). Calpains: physiological \& pathological significance. Pathology, 6: 91-102.

[13] Kakkar, R., Seitz, D.P., Kantham, R., Rajala, R.V.S., Radhi, J.M., Wang, X., Pasha, M.K., Ruiwang and Sharma, R.K. (2002). Calmodulin - dependent cyclic nuclrotidephorphodiesterase in an experimental rat model of cardiac ischaemia - reperfusion. Can J PhysiolPharmacol, 89: 59-66.

[14]Zimmermann, U.J. and Schlaepfer, W.W. (1991). Two stage autolysis of the catalytic subunit initiates activation of calpain I. Biochem. Biophys. Acta.,1078: 192-198.

[15]Enns, D., Karmazyn, M., Mair, J., Lercher, A., Kauntchev, J. and Belcastro,

[16]A. (2002). Calpain, calpastatin activities and ratios during myocardial - ischeamia - reperfusion. Mol Cell Biochem, 241(1-2): 29-35.

[17] Langendorff, O. (1895). Untersuchungen am uberlebendersaugethierherzen. Pflungers. Archiv. Fur. Die. Gesmate. Physiologie.,61: 291-332.

[18] Banka,N., Anand, I.S., Chakravarti, R.N., Sharma,P.L. and Wahi, P.L.(1981). Macroscopic measurements of experimental myocardial infarct sizein rhesus monkeyA comparison of two methods. Bull.P.G.I.,15: 147-150.

[19] Chopra, K., Singh, M., Kaul, N., Andrabi, K.I. and Ganguly, N.K. (1992). Decrease of myocardial infarct size with desferroxamine. Possibble role of oxygen free radicals in its ameliorative effect. Mol. Cell. Biochem, 113: $741-776$

[20] Ausubel, F., Brent, R., Kingston, R.E., Moore, D.D. and Struhl, K.S. (1995). Preparation and analysis of DNA. In: Short Protocol in Molecular Biology. John Wiley \& Sons, Canada, pp. 28-29.

[21] Allen, R.T., Hunter III, W.J. and Aggarwal, D.K. (1997). Morphological and biochemical characterization and analysis of apoptosis. J. Pharmacol. Toxol. Meth.,37: 215-228.

[22] King,J.(1959).A routine method for the estimation of lactic dehydrogenase activity. J. Med. Lab. Tech., 16: 265-272.

[23] Hughes, B. (1961). A method for the estimation of serum creatin kinase and aldose activity in normal and pathological sera. Clin. Chim. Acta.,7: 597-603. 